\title{
Residual Flow Inside the Woven EndoBridge Device at Follow-Up: Potential Predictors of the Bicêtre Occlusion Scale Score 1 Phenomenon
}

\author{
(D) M.T. Nawka, (D) A. Lohse, (D). Bester, (D). Fiehler, and (D).-H. Buhk
}

\begin{abstract}
BACKGROUND AND PURPOSE: The Woven EndoBridge (WEB) device is an established technique for the treatment of intracranial aneurysms. Occasionally, persistent opacification inside the WEB lumen can be observed at follow-up (previously described as Bicêtre Occlusion Scale Score 1). We evaluated potential risk factors of this phenomenon, hypothesizing that initial deviation of the WEB device from the aneurysm axis, size of the aneurysmal neck surface, or inappropriate WEB sizing correlates with Bicêtre Occlusion Scale Score 1 findings.
\end{abstract}

MATERIALS AND METHODS: We systematically reviewed all patients treated with the WEB device between February 2014 and December 2018 in our neurointerventional center. Patients with midterm follow-up DSA available were considered for aneurysm evaluation applying the Bicêtre Occlusion Scale Score. WEB angle deviation from the aneurysm axis, neck widths, and WEB sizes were collected.

RESULTS: We included 65 patients with 67 intracranial aneurysms. Eleven of 67 (16.4\%) intracranial aneurysms showed the Bicêtre Occlusion Scale Score 1 phenomenon at follow-up. Anterior-posterior projections of WEB axis deviation (angles measured in degrees) were significantly different between the Bicêtre Occlusion Scale Score 1 cohort (median \pm interquartile range, $17 \pm 17$ ) and all other Bicêtre Occlusion Scale Scores (median \pm interquartile range, $7 \pm 11 ; P=.023$ ), whereas in lateral projections, no significant difference was observed (median \pm interquartile range, $10 \pm 10$ versus $8 \pm 9 ; P=.169$ ). Neck or aneurysm recurrence, but not the Bicêtre Occlusion Scale Score 1 phenomenon, occurred significantly more often in patients with inappropriate WEB sizing compared with appropriate WEB sizing (median \pm interquartile range, $1 \pm 1.3$ versus $0 \pm 0 ; P<.001 / P=.664$ ).

CONCLUSIONS: The Bicêtre Occlusion Scale Score 1 phenomenon is associated with an initial deviation of the WEB device from the aneurysm axis but does not correlate with aneurysmal neck surface measurements or WEB sizing.

ABBREVIATIONS: AcomA = anterior communicating artery; BOSS = Bicêtre Occlusion Scale Score; IA = intracranial aneurysms; IQR = interquartile range; WOS $=$ WEB Occlusion Scale; WEB $=$ Woven EndoBridge

E ndovascular treatment of wide-neck intracranial aneurysms (IA) with the Woven EndoBridge system (WEB; MicroVention) has been shown to be a reliable approach to provide flow disruption, demonstrating satisfactory aneurysm occlusion rates in previous studies. ${ }^{1-3}$ Due to the risk of recurrence of IA, the performance of follow-up examinations is obligatory, and CTA, MRA, DSA, or flat panel CT are commonly used modalities to verify long-term stability. ${ }^{4-7}$ Contrast opacification inside the

Received February 1, 2020; accepted after revision April 23.

From the Department of Diagnostic and Interventional Neuroradiology, University Medical Center Hamburg-Eppendorf, Hamburg, Germany.

Please address correspondence to Marie T. Nawka, MD, University Medical Center Hamburg-Eppendorf, Martinistr 52, 20246 Hamburg-Eppendorf, Germany; e-mail:m.nawka@uke.de

Indicates article with supplemental on-line photo.

http://dx.doi.org/10.3174/ajnr.A6605
WEB lumen typically occurs during the procedure directly after WEB deployment, but occasionally isolated residual inflow of contrast media into the WEB-carrying dome can be observed at follow-up DSA. ${ }^{6}$ The former WEB Occlusion Scale (WOS) has been revised, and the newer Bicêtre Occlusion Scale Score (BOSS) includes situations with residual intradevice WEB filling, to categorize this finding. ${ }^{6}$ The clinical impact of this phenomenon concerning aneurysm rupture risk and antiaggregation is not yet known, but consideration for retreatment has been emphasized because the risk of rebleeding from ruptured aneurysms after WEB treatment seems to be an issue in this context. ${ }^{6,8}$ Nevertheless, it is important to differentiate isolated residual WEB filling (BOSS 1) and aneurysm remnants or recurrence (BOSS 3), which more frequently require retreatment. ${ }^{6}$

The purpose of our study was to evaluate potential factors determining and influencing the development of BOSS 1 findings 
at midterm follow-up DSA, using a retrospective single-center case series. We primarily hypothesized that axis deviation of the WEB inside the aneurysm might result in residual intradevice filling. This seems logical with regard to the structure of the device: The flow-disrupting effect of the WEB can be considered optimal when the device is located exactly in the direction of the main geometric axis of the aneurysm, leading to blood flow against the proximal recess of the device, where wire density is highest. If the device is tilted, the flow might hit its "shoulder," where wire density decreases substantially compared with the center. This result might lead to incomplete thrombus formation within the WEB. However, it might not necessarily lead to recurrence as long as the neck of the aneurysm is fully covered. Further hypotheses were that a larger aneurysmal neck surface, the width of the WEB device, and suboptimal sizing of the WEB (undersizing) possibly correlate with the occurrence of the BOSS 1 phenomenon at midterm follow-up.

\section{MATERIALS AND METHODS \\ Population}

This retrospective study was conducted in accordance with the 1964 Declaration of Helsinki, and the local ethics review committee waived individual informed consent. We systematically retrospectively reviewed all patients with ruptured and unruptured intracranial aneurysms treated with the WEB device in our neurovascular center between February 2014 and December 2018. Patients with at least 1 midterm follow-up DSA (on average 6 months postprocedure) available were considered in this study.

\section{Endovascular Procedure and Antiaggregation}

Initial DSA examinations and procedures were performed on a biplane angiographic system (Allura Clarity FD 20/20; Philips Healthcare), with the patient under general anesthesia in all procedures. Using transfemoral catheterization, selective series of the respective artery in anterior-posterior and lateral projections were obtained, and a 3D rotational angiography as well as an additional working view projection were acquired. On the basis of the 3D rotational angiography, aneurysm measurements were performed and the appropriate WEB size was chosen. WEB sizing was conducted following the respective recommendations of the company (Sequent Medical; WEB Device Selection Guide; MicroVention). After WEB positioning, a control angiogram was obtained to evaluate appropriate placement and contrast media stasis inside the device. If the WEB position was unsatisfactory, the device was resheathed and repositioned. A final DSA run was conducted after WEB detachment.

Follow-up DSA was performed using transfemoral catheterization and obtaining a selective series of the respective artery in anterior-posterior and lateral projections. Additionally, a dedicated contrast-enhanced flat panel CT scan was acquired, using the neuroangiographic x-ray C-arm (Allura Clarity FD 20/20), equipped with a flat panel detector.

We administered $100 \mathrm{mg}$ of aspirin and $75 \mathrm{mg}$ of clopidogrel 1 week prior to elective treatment of unruptured IA. Periprocedural anticoagulation with $2500 \mathrm{IU}$ of heparin was performed in all cases. In ruptured IA, $250 \mathrm{mg}$ of aspirin was administered during the intervention. In all cases, single antiaggregation with
$100 \mathrm{mg} /$ day of aspirin was continued for 6 weeks postprocedure, unless protrusion of the WEB device into the carrying vessel was observed; in those cases, an additional $75 \mathrm{mg}$ of clopidogrel daily was deemed necessary, and in individual cases, antiaggregation was prescribed for up to 6 months.

\section{Image Analysis}

Our standard follow-up regimen for patients treated with the WEB device includes MRA and DSA at 6 months, and additional long-term follow-up MRA is regularly performed after 18 months. DSA images were evaluated by 2 independent, experienced neuroradiologists with $>4$ years' experience in WEB treatment (J.-H.B. and M.B.). Aneurysm occlusion rates were assessed applying the BOSS: $0=$ no aneurysm filling, $0^{\prime}=$ opacification of the proximal recess, $1=$ opacification inside the $\mathrm{WEB}, 2=$ neck remnant, $3=$ aneurysm remnant with contrast agent inside the sac between the wall and the WEB device. ${ }^{6}$ Residual filling of the WEB device was analyzed using primarily flat panel CT and anterior-posterior and lateral DSA series, respectively. Additional grading of aneurysm occlusion at midterm follow-up DSA and long-term follow-up MRA was assessed according to the WOS: WOS $\mathrm{A}=$ complete aneurysm occlusion, WOS $\mathrm{B}=$ neck remnant, and WOS $\mathrm{C}=$ aneurysm remnant. ${ }^{9}$

All IA were assessed regarding implantation of the WEB device, and potential deviation from the aneurysm axis was measured in lateral and anterior-posterior planes. We subsequently performed arbitrary categorization of each intracranial aneurysm into 1 of the following 3 groups, depending on the extent of deviation: A $\left(0^{\circ}-15^{\circ}\right), \mathrm{B}\left(16^{\circ}-30^{\circ}\right)$, and $\mathrm{C}\left(31^{\circ}-45^{\circ}\right)$. To objectively determine the respective aneurysm axis in each case, we defined it as an orthogonal line toward the aneurysm neck plane. ${ }^{10}$ We further collected the width of each WEB device and all aneurysm neck widths, measuring the largest and smallest diameters, respectively. Aneurysm neck surfaces were calculated by multiplying the minor and major aneurysm neck radii by $\pi$. Additionally, we analyzed WEB sizing for each aneurysm, determining the average aneurysm width from anterior-posterior and lateral projections, measuring the smallest aneurysm height and subsequently matching the chosen WEB device to the Device Selection Table according to the company's latest recommendations (WEB Device Selection Guide), resulting in a dichotomous classification: appropriate or inappropriate WEB sizing.

\section{Statistics}

Quantitative variables were described as mean $\pm \mathrm{SD}$, while qualitative variables were reported as number and percentage. Categoric variables were compared using the $\chi^{2}$ or the Fisher exact test, as appropriate. The Mann-Whitney $U$ test was applied when data did not follow a normal distribution. A $P$ value of .05 was considered statistically significant. Statistical analysis was performed using SPSS Statistics 24.0 (IBM) and Excel 2016 (Microsoft).

\section{RESULTS}

\section{Patient and Aneurysm Characteristics}

The follow-up range for the DSA examinations postprocedure was 5.5-7.8 months (median, 6.1 months) and 14-24 months 
(median, 18 months) for long-term MRA. Regarding the overall collective, 52/65 patients were women (80\%) and 13/65 (20\%) were men, with a mean age of $55.0 \pm 9.6$ years; range, 3081 years. Fifty-three of 67 IA (79.1\%) were unruptured, and 14/67 (20.9\%) IA were treated in the setting of subarachnoid hemorrhage, including 3 cases of retreatment due to aneurysm recurrence after prior coiling or clipping. Forty-six of 67 (68.7\%) IA were located in the anterior circulation (anterior communicating artery [AcomA], 22; MCA, 6; internal carotid artery, 15; anterior choroidal artery, 1; posterior communicating artery, 2), whereas 21/67 (31.3\%) IA were located in the posterior circulation (basilar artery, 17; PICA, 4). Intraoperative thromboembolic events occurred in 2 patients (3.1\%), both treated by intravenous administration of tirofiban and dual-antiplatelet treatment for 3 months, showing no permanent clinical deficits. No contrast agent allergies or periprocedural hemorrhages occurred. In 2 cases, an additional stent was placed. Fifty-two patients were treated with the WEB 21 system, and in 15 patients, the WEB 17 device was implanted. mRS scores at midterm follow-up were available for $53 / 65$ patients $(81.5 \%)$, with 48 patients presenting with an mRS of 0 (90.6\%). The mRS score was 1 in 1 patient (1.9\%), 2 in 3 patients (5.7\%, of whom 2 patients presented with incidental IA, and 1 patient, with a ruptured intracranial aneurysm with a pre-existing mRS of 2 ), and 4 in 1 patient (1.9\%, who had a ruptured intracranial aneurysm). Twelve $\mathrm{mRS}$ values were missing at midterm follow-up.

Isolated residual WEB filling (BOSS 1) at midterm follow-up DSA occurred in 11/67 IA (16.4\%). Of all BOSS 1 cases, 10 (91\%) IA were located in the anterior circulation (AcomA 6; internal carotid artery 3; posterior communicating artery 1 ), whereas $1(9 \%)$ intracranial aneurysm was located in the PICA. All BOSS 1 cases were unruptured aneurysms; no postoperative bleeding occurred in the BOSS 1 collective at midterm follow-up. Three patients (27\%) of the BOSS 1 collective and 8 patients (14\%) of the control group, including the remaining BOSS scores, received antiplatelet therapy (aspirin) at midterm follow-up because antiaggregation was mandatory for at least 6 months in those cases.

Following the WOS grading at midterm follow-up DSA, 9 patients $(82 \%)$ showed complete aneurysm occlusion in the BOSS 1 cohort, 1 patient (9\%) had a neck remnant, and 1 patient (9\%) presented with an aneurysm remnant. In the control collective, 45 patients $(81 \%)$ showed complete aneurysm occlusion, 8 patients (14\%) demonstrated a neck remnant, and in 3 cases (5\%), an aneurysm remnant was detected. We observed no significant difference between the BOSS 1 group and the control cohort at midterm follow-up DSA (median \pm interquartile range [IQR]: $1 \pm 0 ; 1 \pm 0 ; P=.961)$.

Long-term MRA could be performed in 8 patients of the BOSS 1 cohort (73\%), all showing complete aneurysm occlusion (100\%). In the control collective, 32 of 56 patients (57\%) underwent longterm follow-up MRA; 22 patients showed complete aneurysm occlusion (69\%), 8 patients presented with a neck remnant $(25 \%)$, and 2 patients were graded as having aneurysm remnants (6\%).

\section{BOSS Classification}

BOSS grading at midterm follow-up of all IA is shown in Table 1. Three of 11 patients with BOSS 1 had additional long-term
Table 1: BOSS classification of the overall patient cohort according to Caroff et $\mathrm{al}^{6}$

\begin{tabular}{llc}
\hline $\begin{array}{c}\text { BOSS } \\
\text { Classification }\end{array}$ & \multicolumn{1}{c}{ Description } & $\begin{array}{c}\text { Distribution } \\
\text { No. (\%) }\end{array}$ \\
\hline 0 & $\begin{array}{c}\text { No residual flow inside the } \\
\text { aneurysm or the WEB } \\
\text { Opacification of the proximal } \\
\text { recess of the WEB }\end{array}$ & $19(28.4 \%)$ \\
$0^{\prime}$ & $22(32.8 \%)$ \\
1 & Residual flow inside the WEB & $11(16.4 \%)$ \\
2 & Neck remnant & $12(17.9 \%)$ \\
3 & Aneurysm remnant & $3(4.5 \%)$ \\
$1+3$ & Contrast media depicted inside & $0(0 \%)$ \\
& and around the device & \\
\hline
\end{tabular}

follow-up DSA 1 year after initial treatment (27.3\%), whereas 8 patients did not appear for their appointments (72.7\%). In 2 patients, BOSS 1 findings were still verifiable at long-term DSA; in 1 patient, BOSS 1 phenomenon disappeared 1 year after initial therapy (Figure 1).

\section{Deviation of the WEB Device from the Aneurysm Axis}

To determine an exact analysis, we assessed the deviation of the WEB device from the aneurysm axis in both direct (working projection) and perpendicular views on the affected bifurcation using a selective series of the respective artery and $3 \mathrm{D}$ rotational angiography, similar to the projections used for obtaining measures to choose a WEB. See the On-line Figure for an exemplary illustration of axis measurements in an incidental AcomA aneurysm. Following the respective axis measurements, aneurysms of the BOSS 1 cohort and all other BOSS grades were grouped according to their axis deviation angle as described above: $\mathrm{A}\left(0^{\circ}-15^{\circ}\right), \mathrm{B}$ $\left(16^{\circ}-30^{\circ}\right)$, and $\mathrm{C}\left(31^{\circ}-45^{\circ}\right)$. Table 2 provides a detailed presentation of the axis deviation grading for patients in the subgroups BOSS 1 and all other BOSS grades. Axis deviation of the WEB device in an anterior-posterior orientation was significantly different between the BOSS 1 cohort and all other BOSS grades (median \pm IQR: $17 \pm 17$ versus $7 \pm 11 ; P=.023$ ). No significant difference was detected between the 2 groups when assessing lateral projections (median \pm IQR: $10 \pm 10$ versus $8 \pm 9 ; P=.169$ ).

\section{Aneurysm Characteristics and WEB Widths}

No significant difference was detected between patients with BOSS 1 and all other BOSS grades regarding the width of each WEB device according to the measurements of each average aneurysm width and the corresponding WEB-selection table for correct sizing of the device (WEB Device Selection Guide; median \pm IQR: $6 \pm 1$ versus $6 \pm 2 ; P=.296)$.

Aneurysm diameters were measured in millimeters with 2 lengths for each aneurysm and sorted in 2 groups according to the longest and shortest diameters, respectively. No significant differences could be observed between either the BOSS 1 cohort and all other patients concerning the longest neck diameter (median \pm IQR: $4.0 \pm 1.4$ versus $4.0 \pm 1.9 \mathrm{~mm} ; P=.446$ ) or the shortest neck diameter (median $\pm \mathrm{IQR}: 3.1 \pm 1.5$ versus $3.2 \pm$ $1.4 \mathrm{~mm} ; P=.697$ ). Following the calculations described above, aneurysm neck surfaces are indicated in square millimeters. No significant difference was found comparing patients with BOSS 1 and all other BOSS classifications regarding aneurysmal neck 

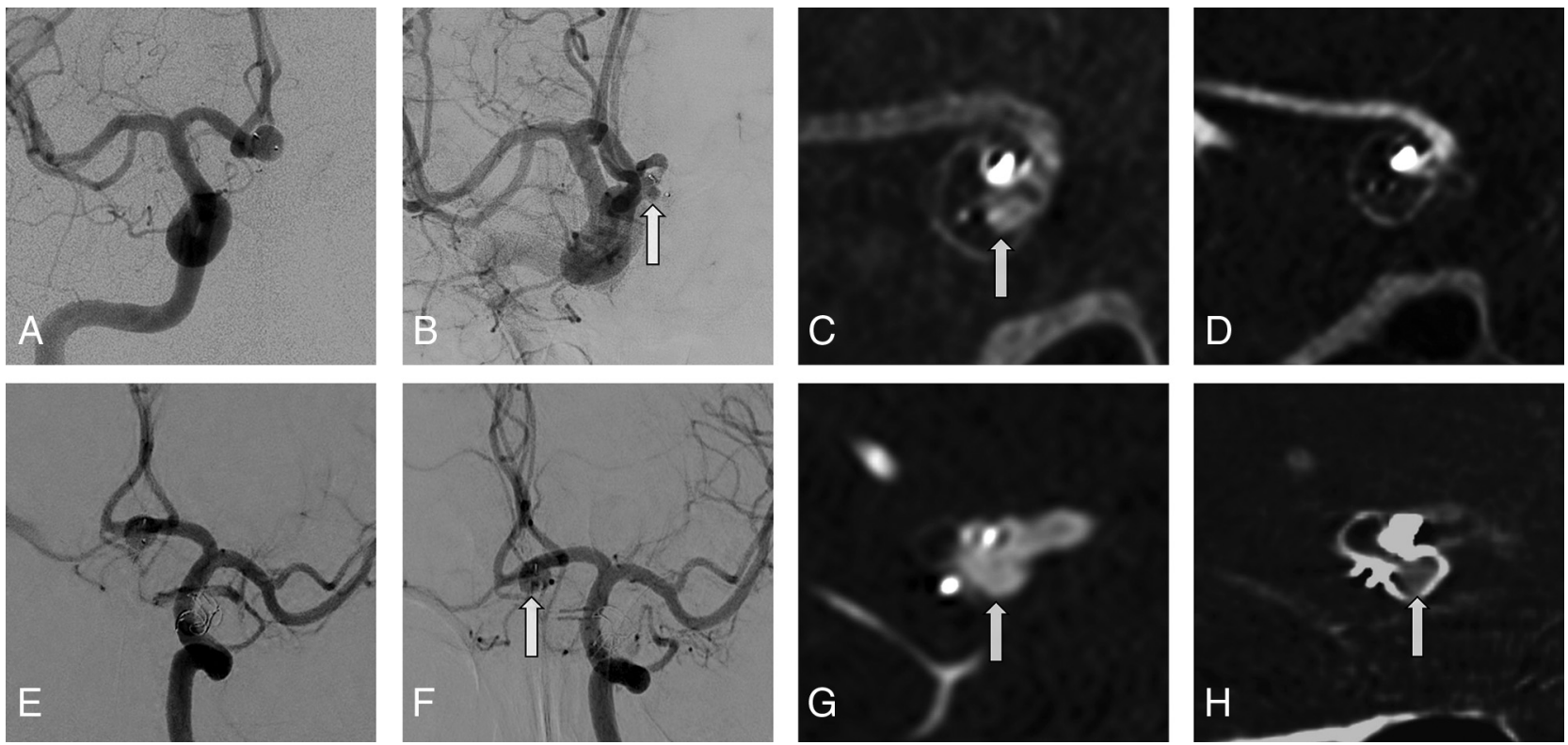

FIG 1. Two different patients (patient 1: $A-D$; patient 2: $E-H$ ) initially presenting with incidental AcomA aneurysms. Arrows indicate residual WEB filling at follow-up examinations (BOSS 1). A, Initial DSA of a patient treated with a WEB 27 device (single-layer, $6 \times 4$ ). $B$, Corresponding followup DSA after 6 months. C, Corresponding follow-up flat panel CT after 6 months. D, Corresponding follow-up flat panel CT after 1 year. Note the clearance of the residual intradevice filling. E, Initial DSA of a patient treated with a WEB 21 device (single-layer, $7 \times 3$ ). $F$, Corresponding follow-up DSA after 7 months. G, Corresponding follow-up flat panel CT after 7 months. $H$, Corresponding follow-up flat panel CT after 1 year. Note the remaining BOSS 1 phenomenon.

Table 2: Grading of axis deviation (WEB device axis from the aneurysm axis)

\begin{tabular}{|c|c|c|c|c|}
\hline & \multicolumn{3}{|c|}{ Collective Distribution (No.) } & \multirow{2}{*}{$\begin{array}{c}\text { Mean } \pm \text { IQR } \\
\text { (BOSS } 1 \text { vs all Other } \\
\text { BOSS Grades), } \\
P \text { Value }\end{array}$} \\
\hline & All (67) & $\begin{array}{l}\text { BOSS } 1 \\
\text { (11) }\end{array}$ & $\begin{array}{l}\text { BOSS } 0,0^{\prime}, \\
2,3(56)\end{array}$ & \\
\hline \multicolumn{5}{|c|}{$\begin{array}{l}\text { Working projection of } \\
\text { bifurcation }\end{array}$} \\
\hline$A\left(0^{\circ}-15^{\circ}\right)$ & 48 (71.6\%) & $4(36.4 \%)$ & $44(78.6 \%)$ & $17 \pm 17$ vs $7 \pm 11, P=.023$ \\
\hline $\mathrm{B}\left(16^{\circ}-30^{\circ}\right)$ & 15 (22.4\%) & $5(45.4 \%)$ & $10(17.8 \%)$ & \\
\hline$C\left(31^{\circ}-45^{\circ}\right)$ & $3(4.5 \%)$ & $2(18.2 \%)$ & $1(1.8 \%)$ & \\
\hline Not ratable & $1(1.5 \%)$ & $0(0.0 \%)$ & $1(1.8 \%)$ & \\
\hline \multicolumn{5}{|c|}{$\begin{array}{l}\text { Perpendicular to } \\
\text { bifurcation }\end{array}$} \\
\hline $\mathrm{A}\left(0^{\circ}-15^{\circ}\right)$ & $58(86.6 \%)$ & $8(72.8 \%)$ & $50(89.3 \%)$ & $10 \pm 10$ vs $8 \pm 9, P=.169$ \\
\hline B $\left(16^{\circ}-30^{\circ}\right)$ & $8(11.9 \%)$ & $2(18.2 \%)$ & $6(10.7 \%)$ & \\
\hline$C\left(31^{\circ}-45^{\circ}\right)$ & $1(1.5 \%)$ & $1(9.0 \%)$ & $0(0.0 \%)$ & \\
\hline
\end{tabular}

\section{DISCUSSION}

Residual intradevice opacification on DSA follow-up examinations is a common finding after WEB treatment; because its etiology and clinical impact are not entirely clarified, this phenomenon requires further analysis. ${ }^{6}$

Because endovascular rating scales for coiling are not satisfactory for assessing aneurysm occlusion rates after WEB deployment, a uniform WEB rating scale has been previously introduced into clinical routine. ${ }^{6}$ The 4 grade WOS was initially proposed by Lubicz et al, ${ }^{9}$ in 2014, and was modified by Caroff et $\mathrm{al}^{6}{ }^{6}$ in 2016, to meet the areas (median \pm IQR: $9.6 \pm 7.6$ versus $10.0 \pm 8.0 \mathrm{~mm}^{2} ; P=$ $.588)$.

\section{WEB Sizing}

In 57/67 patients, WEB sizing was considered appropriate (85.1\%), whereas in 10/67 patients (14.9\%), the WEB device was regarded as undersized $(n=8)$ or oversized $(n=2)$. WEB sizing was not associated with BOSS 1 findings at midterm follow-up $(P=.664)$. Neck or aneurysm recurrence was significantly higher in patients with inappropriate WEB sizing compared with patients with appropriate WEB sizing (median \pm IQR: $1 \pm 1.3$ versus $0 \pm 0 ; P<.001)$. When we compared different WEB generations, no significant difference could be observed between patients treated with the WEB 17 and WEB 21 systems (median \pm IQR: $1 \pm 1$ versus $1 \pm 0 ; P=.227$ ). need of identifying aneurysm subgroups, becoming the Bicêtre Occlusion Scale Score. ${ }^{11,12}$ The BOSS includes grading of residual WEB filling (BOSS 1), though BOSS 1 findings can sometimes be difficult to depict and need to be strictly distinguished from BOSS $1+3$ and BOSS 3 categories. To assess WEB deployment and positioning, flat panel CT has proved highly beneficial. ${ }^{13}$ Aneurysm remnants or recurrent IA (BOSS 3) must be considered for retreatment because they have the risk of rebleeding, whereas in BOSS 1, patients can be observed using subsequent DSA follow-up examinations because the rupture risk is probably low. ${ }^{6}$ Dealing with patients who underwent WEB treatment in the setting of SAH might differ; to date, no reports of rebleeding in BOSS 1 are available, which is consistent with our collective. Furthermore, no reliable data concerning long-term behavior of BOSS 1 findings exist. 
During WEB treatment, adequate positioning of the device inside the aneurysmal sac is a crucial step because incorrect placement requires resheathing and replacement. An ideal alignment of the WEB device to the aneurysm axis is preferable, but sometimes the final position of the device is a compromise due to difficult aneurysm access or aneurysm configuration. If one hypothesized that an initial axis deviation of the device from the aneurysm axis correlates with BOSS 1 findings, this assumption could be partially verified by our results: Axis deviation in the anterior-posterior orientation on midterm follow-up DSA showed correlation to permanent blood flow into the device (BOSS 1).

In addition, most IA in the overall collective were located in the AcomA, where aneurysm access is achieved through the anterior cerebral artery and might sometimes be impeded by sharp curves between these vessels and is thus less straightforward compared with IA located in different areas. Especially in small AcomA aneurysms, catheterization might be challenging and requires consideration of the aneurysm neck orientation. ${ }^{14}$ Complex anatomies in the AcomA region can eventually be overcome using smaller microcatheters with different tip shapes, and variation in the degree of the stiffness of the microcatheter could additionally be valuable, thus potentially improving microcatheter stability inside the aneurysm dome. ${ }^{14-16}$

If the microcatheter cannot be located in the anatomic center of the aneurysm dome, WEB deployment must be conducted from an oblique starting position. Because this course of axis deviation is difficult to ascertain from lateral projections, this difficulty might explain the missing correlation between BOSS 1 findings and determination of the lateral axis deviation. Because hemodynamic conditions and flow dynamics are crucial factors in the development of aneurysm recurrence, the AcomA location might be of high importance for the development of residual WEB filling because flow conditions are particularly complex in the AcomA region. ${ }^{17-19}$ Hemodynamic studies confirmed that blood flow was faster in wide-neck IA ${ }^{20}$ however, the presence of a wide aneurysm neck as a risk factor for the development of aneurysm recurrence after WEB treatment could not be confirmed in our study. This issue might be explained by a relatively small range of neck widths in our collective $(1.4-6.9 \mathrm{~mm})$. Following aneurysm morphometrics, we furthermore aimed to assess the potential impact of aneurysm neck diameters and aneurysmal neck surfaces on the BOSS 1 phenomenon. Most interesting, this assumption could not be confirmed by our statistics; however, our results are in line with a recently published study by Goertz et al, ${ }^{21}$ detecting no correlation between maximum aneurysm diameter/neck width and procedure-related complications after WEB treatment.

Not only correct deployment of the device but also WEB sizing is a crucial issue during the treatment process, and the official WEB-sizing scale recommends an appropriate choice of the device (WEB Device Selection Guide). Inappropriate sizing of the WEB device was found to be uncommon in patients with BOSS 1 , whereas oversizing or undersizing of the WEB device resulted in substantially higher neck or aneurysm recurrence rates at follow-up. According to these findings, Cagnazzo et $\mathrm{al}^{22}$ confirmed that undersizing of the WEB device is more common in incompletely occluded unruptured and ruptured IA. Especially in the setting of treating ruptured IA, the primary objective is fast aneurysm occlusion, and imperfect WEB sizing can more likely be accepted than in the treatment of incidental IA where substantial case preparation is obligatory. However, assessment of BOSS 1 findings in ruptured aneurysms needs to be further evaluated in larger future studies. Following aneurysm treatment with the WEB device, adequate follow-up examinations are deemed necessary because aneurysm occlusion rates differ between unruptured and ruptured IA. ${ }^{3}$ However, visualization of the WEB cavity and thus detection of BOSS 1 phenomenon in MRA is impeded due to radiofrequency shielding effects. ${ }^{23}$ Therefore, BOSS 1 verification should generally be performed by DSA or flat panel CT. ${ }^{13,23}$

\section{Limitations}

This study had several limitations. First, it was a retrospective analysis based on a relatively small single-center population. Additionally, we evaluated only the first (midterm) follow-up DSA. Because BOSS 1 cases might decrease and available DSA examinations after 12 months were sparse in our patient cohort, the rate of BOSS 1 findings after 1 year needs to be evaluated in further studies aiming to assess its clinical relevance. Because the impact of BOSS 1 findings might be higher in ruptured aneurysms due to the additional risk of aneurysm re-rupture, a potential correlation should be evaluated in future studies because our collective could not provide enough ruptured WEB cases.

\section{CONCLUSIONS}

Occurrence of the BOSS 1 phenomenon at midterm follow-up is a common finding in patients treated with the last 2 generations of the WEB device, showing an association with the initial deviation of the WEB device from the aneurysm axis. Inappropriate WEB sizing does not typically lead to BOSS 1 phenomenon, but it is a risk factor for neck or aneurysm recurrence. To further assess the clinical impact of the BOSS 1 phenomenon, long-term follow-up DSA examinations will be useful to evaluate potential correlations among BOSS 1 findings, aneurysm recurrence, and rebleeding.

Disclosures: Jens Fiehler-UNRELATED: Consultancy: Acandis, Cerenovus, Medtronic, MicroVention, Stryker; Grants/Grants Pending: Acandis, Cerenovus, Medtronic, MicroVention, Stryker; Payment for Lectures Including Service on Speakers Bureaus: Penumbra;* Stock/Stock Options: Tegus Corporation; OTHER RELATIONSHIPS: Managing Director of Eppdata. Jan-Hendrik BuhkUNRELATED: Consultancy: Acandis, Cerenovus, MicroVention, Stryker; Employment: University Hospital Hamburg-Eppendorf. *Money paid to individual.

\section{REFERENCES}

1. van Rooij S, Sprengers ME, Peluso JP, et al. A systematic review and meta-analysis of Woven EndoBridge single layer for treatment of intracranial aneurysms. Interv Neuroradiol 2020 Feb 6. [Epub ahead of print] CrossRef Medline

2. Kaya HE, Bakdik S, Keskin F, et al. Endovascular treatment of intracranial aneurysms using the Woven EndoBridge (WEB) device: retrospective analysis of a single center experience. Clin Imaging 2020;59:25-29 CrossRef Medline

3. Zhang SM, Liu LX, Ren PW, et al. Effectiveness, safety and risk factors of Woven EndoBridge device in the treatment of wide-neck intracranial aneurysms: systematic review and meta-analysis. World Neurosurg 2020;136:e1-23 CrossRef Medline 
4. Ozpeynirci Y, Braun M, Schmitz B. CT angiography in occlusion assessment of intracranial aneurysms treated with the WEB device. J Neuroimaging 2019;29:481-86 CrossRef Medline

5. Mine B, Tancredi I, Aljishi A, et al. Follow-up of intracranial aneurysms treated by a WEB flow disrupter: a comparative study of DSA and contrast-enhanced MR angiography. J Neurointerv Surg 2016;8:615-20 CrossRef Medline

6. Caroff J, Mihalea C, Tuilier T, et al. Occlusion assessment of intracranial aneurysms treated with the WEB device. Neuroradiology 2016;58:887-85 CrossRef Medline

7. van Rooij S, Peluso JP, Sluzewski M, et al. Mid-term 3T MRA follow-up of intracranial aneurysms treated with the Woven EndoBridge. Interv Neuroradiol 2018;24:601-07 CrossRef Medline

8. Cognard C, Januel AC. Remnants and recurrences after the use of the WEB intrasaccular device in large-neck bifurcation aneurysms. Neurosurgery 2015;76:522-30 CrossRef Medline

9. Lubicz B, Klisch J, Gauvrit JY, et al. WEB-DL endovascular treatment of wide-neck bifurcation aneurysms: short- and midterm results in a European study. AJNR Am J Neuroradiol 2014;35:432-38 CrossRef

10. Duan Z, Li Y, Guan S, et al. Morphological parameters and anatomical locations associated with rupture status of small intracranial aneurysms. Sci Rep 2018;8:6440 CrossRef Medline

11. Caroff J, Mihalea C, Ikka L, et al. Interobserver variability in the assessment of aneurysm occlusion with the WEB aneurysm embolisation system. J Neurointerv Surg 2017;9:e11-12 CrossRef Medline

12. Fiorella D, Arthur A, Byrne J, et al. Interobserver variability in the assessment of aneurysm occlusion with the WEB aneurysm embolization system. J Neurointerv Surg 2015;7:591-95 CrossRef Medline

13. Caroff J, Mihalea C, Neki H, et al. Role of C-arm VasoCT in the use of endovascular WEB flow disruption in intracranial aneurysm treatment. AJNR Am J Neuroradiol 2014;35:1353-57 CrossRef Medline

14. Asif KS, Sattar A, Lazzaro MA, et al. Consecutive endovascular treatment of 20 ruptured very small $(<3 \mathrm{~mm})$ anterior communicating artery aneurysms. Interv Neurol 2016;5:57-64 CrossRef Medline
15. Sluzewski M, Bosch JA, van Rooij WJ, et al. Rupture of intracranial aneurysms during treatment with Guglielmi detachable coils: incidence, outcome, and risk factors. J Neurosurg 2001;94:238-40 CrossRef Medline

16. Wang CC, Lv N, Feng ZZ, et al. Intra-aneurysmal microcatheter looping technique for stent-assisted embolization of complex intracranial aneurysms. Interv Neuroradiol 2015;21:580-84 CrossRef Medline

17. Luo B, Yang X, Wang S, et al. High shear stress and flow velocity in partially occluded aneurysms prone to recanalization. Stroke 2011;42:745-53 CrossRef Medline

18. Huang DZ, Jiang B, He W, et al. Risk factors for the recurrence of an intracranial saccular aneurysm following endovascular treatment. Oncotarget 2017;8:33676-82 CrossRef Medline

19. Castro MA, Putman CM, Sheridan MJ, et al. Hemodynamic patterns of anterior communicating artery aneurysms: a possible association with rupture. AJNR Am J Neuroradiol 2009;30:297-302 CrossRef Medline

20. Tateshima S, Chien A, Sayre J, et al. The effect of aneurysm geometry on the intra-aneurysmal flow condition. Neuroradiology 2010; 52:1135-41 CrossRef Medline

21. Goertz L, Liebig T, Siebert E, et al. Risk factors of procedural complications related to Woven EndoBridge (WEB) embolization of intracranial aneurysms. Clin Neuroradiol 2019 Feb 7. [Epub ahead of print] CrossRef Medline

22. Cagnazzo F, Ahmed R, Zannoni R, et al. Predicting factors of angiographic aneurysm occlusion after treatment with the Woven EndoBridge device: a single-center experience with midterm follow-up. AJNR Am J Neuroradiol 2019;40:1773-78 CrossRef Medline

23. Nawka MT, Sedlacik J, Frölich A, et al. Multiparametric MRI of intracranial aneurysms treated with the Woven EndoBridge (WEB): a case of Faraday's cage? J Neurointerv Surg 2018;10:988-94 CrossRef Medline 